\title{
ADP/ATP Translocase 2
}

National Cancer Institute

\section{Source}

National Cancer Institute. ADP/ATP Translocase 2. NCI Thesaurus. Code C37301.

ADP/ATP translocase 2 (298 aa, $\sim 33 \mathrm{kDa}$ ) is encoded by the human SLC25A5 gene. This protein plays a role in the transport of ADP and ATP across the inner mitochondrial membrane and may be involved in mitotic chromosome segregation. 